\title{
ПРОФЕССИОНАЛЬНОЕ РАЗВИТИЕ
}

УДК 378

DOI 10.23951/1609-624X-2018-5-212-217

\section{ФОРМИРОВАНИЕ ИНФОРМАЦИОННО-ЗНАНИЕВОГО ПОТЕНЦИАЛА НА ОСНОВЕ ИСПОЛЬЗОВАНИЯ МЕТОДИКИ ОТБОРА ИНФОРМАЦИОННЫХ РЕСУРСОВ}

\author{
О. Е. Пудовкина, Т. Н. Гороховицкая, Ю. А. Тихонов, Ю. О. Гороховицкая
}

Сызранский филиал Самарского государственного экономического университета, Сызрань

\begin{abstract}
Рассматривается вопрос формирования собственных библиотечных фондов образовательной организации с использованием методики отбора информационных ресурсов. Представлены результаты изучения системы обучения на основе методов и технологий, обеспечивающих высокий уровень образовательного процесса, научно-исследовательских и технических разработок, которые являются одной из главных задач, стоящих в условиях новых стандартов ФГОС третьего поколения. Дана детальная характеристика процессу создания нового знания как основного интеллектуального ресурса, определяющего конкурентное преимущество индивида. Рассмотрена структура информационных ресурсов, обеспечивающих научно-познавательную деятельность. Описаны способы отбора информационных ресурсов, основанные на комплексном подходе по отбору наиболее значимых периодических изданий с целью пополнения информационно-знаниевого потенциала. Предложенная методика позволяет решить задачу инновационного характера: от комплектования собственных фондов и формирования своего перечня приоритетных изданий до накопления собственного знаниевого потенциала.
\end{abstract}

Ключевые слова: информационно-знаниевый потенциал, новое знание, информационное обеспечение, отбор информационных ресурсов, процесс создания нового знания.

В Концепции долгосрочного социально-экономического развития Российской Федерации необходимым условием формирования инновационной экономики названа модернизация системы образования как основа динамичного экономического роста и социального развития общества $[1$, с. 260]. Поэтому с целью обеспечения высокого уровня образовательного процесса, исследовательских и технических исследований необходимо осуществление инновационных разработок в сфере высшего профессионального образования.

Совершенствование системы обучения на основе методов и технологий, обеспечение высокого уровня образовательного процесса, исследовательских и технических разработок - одни из главных задач, которые необходимо решать в условиях новых стандартов ФГОС $3+$, которые актуализировали новые способы деятельности [2, с. 194]. Совершенно очевидным становится тот факт, что для успешного управления помимо традиционных методических подходов целесообразно разработать решения по управлению знаниями обучающихся.

Современные тенденции таковы, что наряду с информацией в качестве ресурса рассматривается и знание как «необходимая информация, задаваемая с явными правилами с учетом процедур и таких отношений, как понимание, одобрение, согласие» (автор Ф. Махлуп). Согласно П. Друкеру, зна- ние - это информация, которая имеет практическую ценность и служит для получения конкретных результатов. В современных условиях способность использовать совокупные знания и умения для разрешения конкретных задач, ситуаций и проблем, возникающих в личной и профессиональной жизнедеятельности, становится важнее энциклопедической грамотности [3, с. 143].

В связи с этим высокую степень актуальности имеют вопросы информационного обеспечения процесса обучения. Получение эффективного результата возможно при условии использования информационных технологий и образовательных ресурсов нового поколения [4, с. 77]. Несмотря на наличие большого количества работ в данной области, методика отбора информационных данных для обучения имеет большой потенциал для исследований [5].

Как известно, знание является основой развития любой системы или процесса. Остановимся более подробнее на процессе создания нового знания (рис. 1).

Детальная оценка процесса создания нового знания дает возможность сделать вывод, что его формирование невозможно без нижеперечисленных норм:

- информационного обеспечения, т. е. без использования информационных ресурсов; 


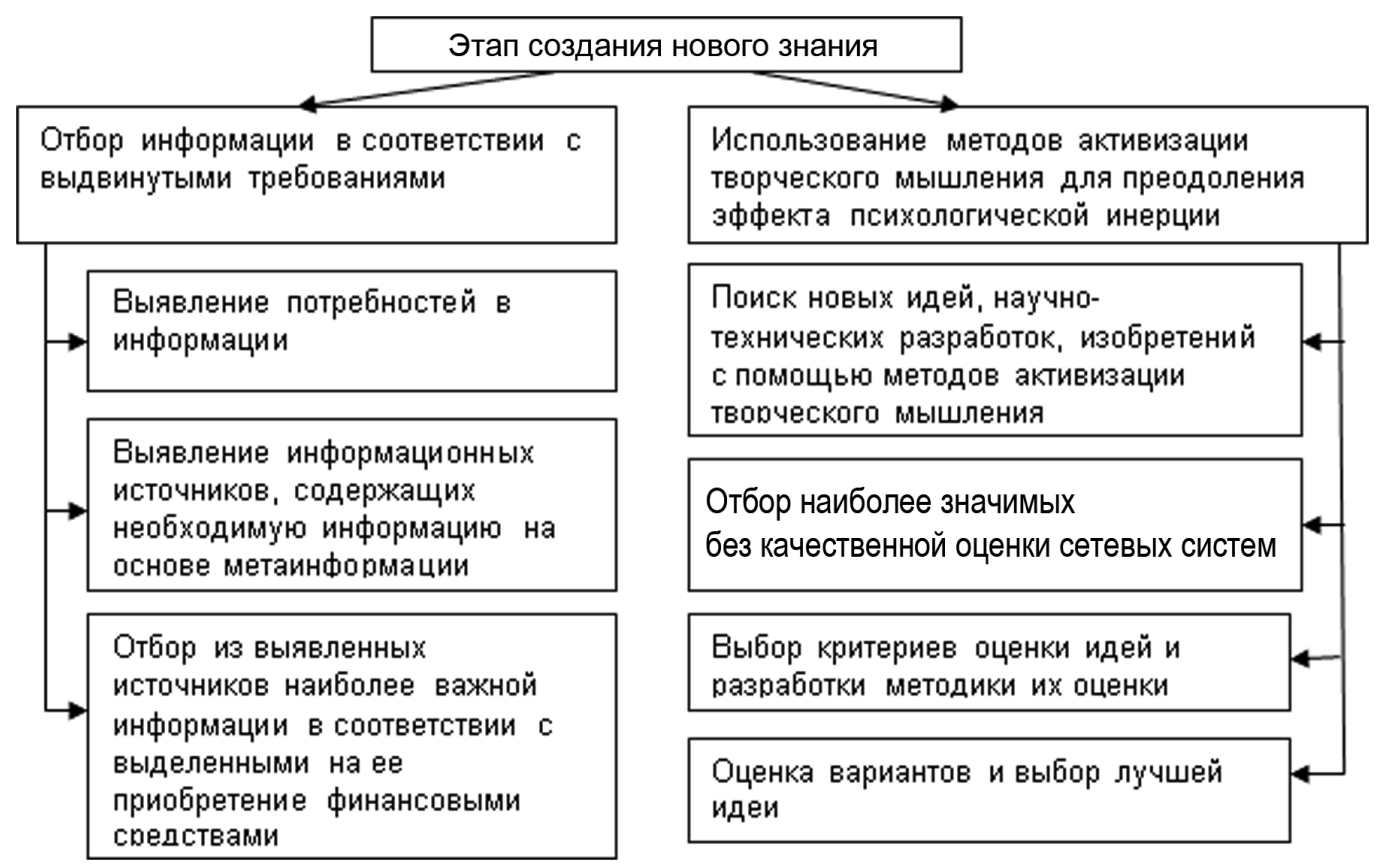

Рис. 1. Процесс создания нового знания

- эффективной работы с информационными данными, в том числе и мировыми информационными ресурсами;

- процесса развития творческого мышления и применения способов активизации творческой мысли для возникновения нового знания.

Невозможно представить себе качественный проект, при управлении которым не применяются методы и инструменты работы со знаниями, поскольку в условиях современной экономики знаний главенствующим ресурсом, определяющим конкурентное преимущество, является ресурс интеллектуальный.

Также рынок труда предъявляет новые требования к кадрам, где центральными по значимости становятся работники высокой квалификации, обладающие достаточной степенью готовности к непрерывному образованию через всю жизнь и к самообразованию, владеющие значительным уровнем научно-исследовательской компетенции и знаниями в различных областях.

Для создания нового знания нужен процесс, позволяющий сделать труднодоступные знания понятными и доступными для восприятия. Для запуска такого процесса необходимо преобразовывать явные, скрытые знания в объяснимую информацию. Информационные ресурсы являются важнейшей составляющей развития информационно-знаниевого потенциала. Поэтому в качестве инструментов управления знаниями может быть использована методика отбора информационных данных.

Несомненно, информационное обеспечение должно носить системный и комплексный харак- тер. Анализ потребностей, необходимых для проведения научно-исследовательских работ и пополнения знаний, позволил сформировать структуру информационных данных и ресурсов знаний, обеспечивающих научную деятельность: периодические издания, профессиональные базы данных, ресурсы всемирной сети Интернет, библиотеки, патенты (рис. 2).

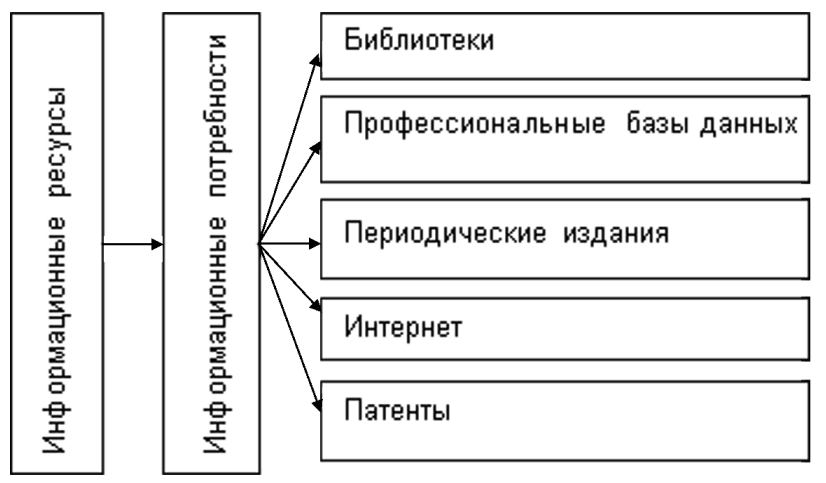

Рис. 2. Структура информационных ресурсов, обеспечивающих научно-познавательную деятельность

Проанализировав и обобщив информационные ресурсы с позиции использования информационных данных в научно-исследовательской работе, автор уделяет центральное внимание периодическим изданиям, профессиональным базам данных, для которых был разработан методический инструментарий их эффективного отбора.

Формирование нового знания и развитие творческих способностей, на взгляд авторов, происходит с помощью нижеуказанного методического 
инструментария информационного обеспечения, организация которого выражается на основе отбора наиболее ценных источников информации в периодических изданиях и профессиональных базах данных.

На этапе образования нового знаниевого потенциала следует применять приемы научно-технического творчества, дающие возможность активизировать креативное мышление, подавлять инертность, производить инновационные и конкурентоспособные по сравнению с мировыми брендами идеи. Систематизировав опыт отечественных и зарубежных исследований в области усиления творческого потенциала и образования нового знания, автор предложил методы их активизации, указанные на рис. 3.

На сегодняшний день увеличивающийся поток информации и высокая стоимость доступа остро поставила вопрос о рациональном использовании информационных ресурсов. Встает вопрос об эффективном отборе информации, которая бы отвечала по качественным критериям, таким как полнота, достоверность, оперативность, ценность.

Периодические издания, патенты и профессиональные базы данных есть важнейшие информационные ресурсы в научной деятельности. Результаты научных достижений в основном публикуются в периодических изданиях. Исключительное значение периодические издания имеют в экономике, где предъявляются повышенные требования к информации, и отличаются значительной глубиной отражения знаний в той или иной области [6].

Общепризнанной методики отбора информационных данных в настоящее время не существует. Сформированная авторская методика позволяет из всего массива информационных данных отобрать наиболее значимый информационный ресурс для пополнения информационно-знаниевого потенциала. Данная методика видится наиболее эффективной, так как при ее выработке применены существующие подходы к отбору периодических изданий как российского, так и зарубежного потока, применительно к научной деятельности в целях формирования нового знания. Выделение наиболее информативных изданий позволяет сформировать основу инновационных конкурентоспособных идей.

Суть методики сводится к следующему. За основу в работе с информационными данными был взят электронный каталог Ulrich International Periodikals Directori американского издания Bowker, который по полноте охвата и оперативности не имеет аналогов на сегодняшний день. Он включает более 300 тыс. периодических изданий $[7,8]$.

Методика отбора информационных данных с целью проведения научно-исследовательских работ и получения нового знания создана на основе определения ценности издания, при этом ценность издания рассматривается как производная от нескольких составляющих - наиболее значимых параметров, описывающих издание. Описание каждого издания включает параметры: полнота информации, цена, периодичность и другие. Посредством тщательного анализа были выделены наиболее значимые параметры, характеризующие значимость журнала:

- число служб, реферирующих издание;

- количество служб, имеющих в своих фондах данное издание;

- импакт-фактор издания - показатель ценности журнала, который ежегодно рассчитывается американским Институтом научной информации и результаты публикуются в журнале Citation Report. Он охватывает огромное количество резецензируемых журналов по 227 дисциплинам. Для мировых информационных служб данный показатель демонстрирует ценность издания. Способ его расчета основан на трехлетнем периоде:

- регулярность выхода издания;

- реферирование издания;

- наличие у издания веб-сайта;

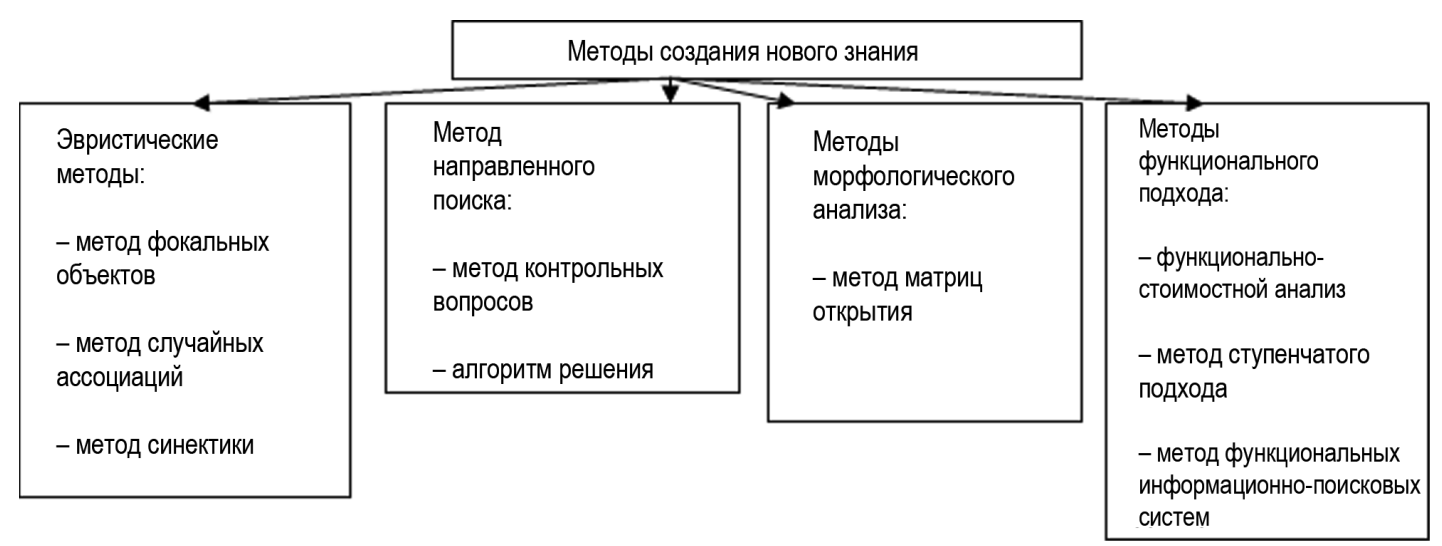

Рис. 3. Методы создания нового знания 
- онлайн-доступ к изданию;

- принадлежность к странам-лидерам в данной отрасли $[9,10]$.

Важность и ценность периодических журналов устанавливается определенным набором параметров. После установления значимости изданий им присуждается оценка, и на ее основе издания представляются в форме ранжированного перечня. Способ ранжирования в такой ситуации наиболее полезен, так как дает возможность упорядочить объекты в соответствии с их качеством. В этом случае ранжирование периодических изданий позволяет находить приоритеты при выборе журналов как по их значимости, так и по цене, т. е. издание представляется в форме ранжированного списка с указанием ему ранга и цены. Указанная методика состоит из взаимосвязанных этапов, каждый из которых характеризуется своей спецификой.

Сформированная методика представляется следующей последовательностью.

1-й этап: отбор информационных ресурсов из информационного каталога Ulrich International Periodikals Directori выполняется автоматически.

1. Отбирается одна или несколько предметных рубрик, определяющих интересную тематическую направленность издания.

2. Выбирается издание, которое обладает параметрами, выделенными автором в качестве основополагающих: наличие импакт-фактора, регулярность выпуска, наличие рецензирования статей, наличие веб-сайта у издания.

2-й этап: экспертная оценка каждого из отобранных изданий.

1. Издания рецензируются по трем характеристикам: величина импакт-фактора издания, коли- чество служб, имеющих в своих фондах издание и предоставляющих к нему доступ, количество реферативных служб, обрабатывающих издание. При оценке изданий по этим параметрам принимаются во внимание их натуральные величины. На основе этих величин присваиваются числовые ранги по каждой характеристике. Среднее значение этих рангов служит конечным рангом издания:

$\mathrm{BN}=\left(\mathrm{N}_{1 \mathrm{i}}+\mathrm{N}_{2 \mathrm{i}}+\mathrm{N}_{3 \mathrm{i}}\right) / 3$,

где $\mathrm{BN}$ - связанный ранг издания; $\mathrm{N}_{1 \mathrm{i}}$ - ранг по показателю аннотируемости издания і-го значения; $\mathrm{N}_{2 \mathrm{i}}$ - ранг по фактору наличия издания в фондах крупных мировых научных центров і-го объекта; $\mathrm{N}_{3 \mathrm{i}}$ - ранг по фактору цитируемости издания i-го объекта; $\mathrm{Ni}$ - ранжируемый объект (издание).

2. Ранжирование изданий в форме перечня с указанием числового ранга, присвоенного журналу, и его цены. В этом случае ранг, равный единице, присваивается наиболее важному изданию, а ранг, равный двум, присваиваются следующему по важности изданию и т. д. [6].

Таким образом, выработана методика, основанная на обобщенном подходе по отбору наиболее ценных периодических изданий с целью пополнения информационно-знаниевого потенциала. Кроме того, методики ориентированы на отбор информационных данных для решения необходимого круга задач (комплектование библиотечных фондов), в том числе и инновационного направления. Анализируемая методика способствует решению ряда самых разнообразных задач: от формирования собственных фондов и создания своего перечня приоритетных изданий для накопления собственного знаниевого потенциала до эффективного управления образовательной организацией.

\section{Список литературы}

1. Обухов В. В., Войтеховская М. П., Ревякина В. И. Вклад Томского государственного педагогического университета в решение задач педагогического образования и социально-экономического развития Сибири // Вестн. Томского гос. пед. ун-та (TSPU Bulletin). 2012. Вып. 3 (118). С. 260-267.

2. Поздеева С. И. Особенности гуманитарного управления инновациями для становления профессионализма педагога начальной школы // Вестн. Томского гос. пед. ун-та (TSPU Bulletin). 2013. Вып. 9 (137). С. 194-196.

3. Обухов В. В., Поздеева С. И Модернизация содержания педагогического образования с позиции компетентностного подхода // Сборник статей Федерального агентства по образованию. Томск, 2008. С. 143.

4. Обухов В. В., Войтеховская М. П., Сартакова Е. Е. Модели персонифицированного и индивидуализированного повышения квалификации работников образования: постановка задач исследования // Вестн. Томского гос. пед. ун-та (TSPU Bulletin). 2013. Bып. 13 (141). C. $77-81$.

5. Пудовкина О. Е. Совершенствование информационного обеспечения маркетинговой деятельности предприятий машиностроительного комплекса: дис. ... канд. эконом. наук. Самара, 2013.

6. Элькина Л. В. Совершенствование инсормационного обеспечения инновационной деятельности компании: дис. .... канд. эконом. наук. M., 2010.

7. Федеральный закон Российской Федерации «Об информации, информационных технологиях и о защите информации» от 27.07 .2006 № $149-Ф 3$.

8. Письмо Президента РФ «Основы политики Российской Федерации в области развития науки и технологий на период до 2010 года и дальнейшую перспективу» от 30.03.2002 № ПР-576. 
9. Федеральный закон Российской Федерации «О внесении изменений в Федеральный закон „Об обязательном экземпляре документов“» от 26 марта 2008 г. № 28-Ф3.

10. Постановление Правительства РФ «Об утверждении правил распространения периодических печатных изданий по подписке» от 2 августа 1997 г. № 976.

Ольга Евгеньевна Пудовкина, кандидат экономических наук, доцент, Сызранский филиал Самарского государственного экономического университета (ул. Людиновская, 23, Сызрань, Россия, 446023). E-mail: olechkasgeu@mail.ru

Татьяна Николаевна Гороховицкая, кандидат экономических наук, доцент, Сызранский филиал Самарского государственного экономического университета (ул. Людиновская, 23, Сызрань, Россия, 446023).

Юлия Олеговна Гороховицкая, старший преподаватель, Сызранский филиал Самарского государственного экономического университета (ул. Людиновская, 23, Сызрань, Россия, 446023).

Юрий Алексеевич Тихонов, кандидат экономических наук, доцент, Сызранский филиал Самарского государственного экономического университета (ул. Людиновская, 23, Сызрань, Россия, 446023).

Материал поступил в редакциию 12.02.2018.

DOI 10.23951/1609-624X-2018-5-212-217

\section{FORMING INFORMATION-KNOWLEDGE POTENTIAL USING THE METHOD OF SELECTING INFORMATION RESOURCES}

\section{O. E. Pudovkina, T. N. Gorokhovitskaya, Yu. A. Tikhonov, Yu. O. Gorokhovitskaya}

\section{Syzran branch of Samara State University of Economics, Syzran, Russian Federation}

The issue of formation of the library's own funds of the educational organization with the use of the method of selection of information resources is considered. The results of studying the training system on the basis of methods and technologies providing a high level of the educational process, research and development, which are one of the main tasks facing the new standards of GEF $3+$ are presented. It is quite obvious that for successful management, in addition to traditional methodological approaches, it is advisable to develop solutions for knowledge management of students. A detailed description of the process of creating new knowledge as the main management of an intellectual resource that determines the competitive advantage of an individual is given. The structure of information resources providing scientific and cognitive activity is considered. To create new knowledge, a process is needed that makes hard-to-reach knowledge understandable and accessible to perception. To start such a process, convert explicit, hidden knowledge into explanatory information. Information resources are an important component of the development of information and knowledge capacity. Therefore, the methodology for selecting information data can be used as knowledge management tools. The ways of selection of information resources based on the complex approach on selection of the most important periodicals with the purpose of updating information and knowledge potential are described. The proposed methodology allows to solve an innovative task: from the acquisition of own funds and the formation of its list of priority publications to the accumulation of its own knowledge potential.

Key words: information-knowledge potential, new knowledge, information support, selection of information resources, the process of creating new knowledge.

\section{References}

1. Obukhov V. V., Voytekhovskaya M. P., Revyakina V. I. Vklad Tomskogo gosudarstvennogo pedagogicheskogo universiteta v reshenie zadach pedagogicheskogo obrazovaniya i sotsial'no-ekonomicheskogo razvitiya Sibiri [Contribution of the Tomsk State Pedagogical University in solving problems of pedagogical education and social and economic development of Siberia]. Vestnik Tomskogo gosudarstvennogo pedagogicheskogo universiteta - TSPU Bulletin, 2012, vol. 3 (118), pp. 260-267 (in Russian).

2. Pozdeeva S. I. Osobennosti gumanitarnogo upravleniya innovatsiyami dlya stanovleniya professionalizma pedagoga nachal'noy shkoly [The humanitarian features of innovation for the teacher competence formation at primary school]. Vestnik Tomskogo gosudarstvennogo pedagogicheskogo universiteta - TSPU Bulletin, 2013, vol. 9 (137), pp. 194-196 (in Russian).

3. Obukhov V. V., Pozdeeva S. I. Modernizatsiya soderzhaniya pedagogicheskogo obrazovaniya s pozitsii kompetentnostnogo podkhoda [Modernization of the content of pedagogical education from the position of competence approach]. Sbornik statey Federal'nogo agentstva po obrazovaniyu [Collection of articles of the Federal Agency for Education]. Tomsk, 2008. Pp. 143 (in Russian).

4. Obukhov V. V., Voytekhovskaya M. P., Sartakova E. E. Modeli personifitsirovannogo i individualizirovannogo povysheniya kvalifikatsii rabotnikov obrazovaniya: postanovka zadach issledovaniya [Personalized and individualized models of teacher training: setting objectives of the study]. Vestnik Tomskogo gosudarstvennogo pedagogicheskogo universiteta - TSPU Bulletin, 2013, vol. 13 (141), pp. $76-81$ (in Russian). 
5. Pudovkina O. E. Sovershenstvovaniye informatsionnogo obespecheniya marketingovoy deyatel'nosti predpriyatiy mashinostroitel'nogo kompleksa. Dis. kand. ekonom. nauk [Perfection of information support of marketing activity of the enterprises of a machine-building complex. Diss. cand. econ. sci.]. Samara, 2013.143 p. (in Russian).

6. El'kina L. V. Sovershenstvovaniye informatsionnogo obespecheniya innovatsionnoy deyatel'nosti kompanii. Dis. kand. ekonom. nauk [Improvement of information support for the company's innovation activities. Diss. cand. econ. sci.]. Moscow, 2010. 127 p. (in Russian).

7. Federal'nyy zakon Rossiyskoy Federatsii “Ob informatsii, informatsionnykh tekhnologiyakh i o zashchite informatsii” ot 27.07.2006 g. no. 149-FZ [Federal Law of the Russian Federation "On information, information technologies and information protection" no. 149-FZ of July 27, 2006] (in Russian).

8. Pis'mo Prezidenta RF "Osnovy politiki Rossiyskoy Federatsii v oblasti razvitiya nauki i tekhnologiy na period do 2010 goda i dal'neyshuyu perspektivu" ot 30.03.2002 g. no. PR-576 [Letter of the President of the Russian Federation "Fundamentals of the policy of the Russian Federation in the field of science and technology development for the period until 2010 and further prospects" of March 30, 2002 no. PR-576] (in Russian).

9. Federal'nyy zakon Rossiyskoy Federatsii "O vnesenii izmeneniy v Federal'nyy zakon "Ob obyazatel'nom ekzemplyare dokumentov" ot 26 marta 2008 g. no. 28-FZ [The Federal Law of the Russian Federation "On Amendments to the Federal Law "On a mandatory copy of documents" dated March 26, 2008 no. 28-FZ] (in Russian).

10. Postanovleniye Pravitel'stva RF "Ob utverzhdenii pravil rasprostraneniya periodicheskikh pechatnykh izdaniy po podpiske" ot 2 avgusta $1997 \mathrm{~g}$. no. 976 [Resolution of the Government of the Russian Federation "On approval of the rules for the distribution of periodical print publications by subscription" dated by August 2, 1997 no. 976] (in Russian).

Pudovkina O. E., Syzran branch of Samara State University of Economics (ul. Lyudinovskaya, 23, Syzran, Russian Federation, 446023). E-mail: olechkasgeu@mail.ru

Gorokhovitskaya T. N., Syzran branch of Samara State University of Economics (ul. Lyudinovskaya, 23, Syzran, Russian Federation, 446023). E-mail:

Gorokhovitskaya Yu. O., Syzran branch of Samara State University of Economics (ul. Lyudinovskaya, 23, Syzran, Russian Federation, 446023). E-mail:

Tikhonov Yu. A., Syzran branch of Samara State University of Economics (ul. Lyudinovskaya, 23, Syzran, Russian Federation, 446023). E-mail: 